\title{
BUKU POP-UP UNTUK PEMBELAJARAN BERCERITA SISWA SEKOLAH DASAR
}

\section{Rachmadini Nur Fadillah \& Ika Lestari \\ e-mail: fadillahrachmadini@gmail.com \\ Pendidikan Guru Sekolah Dasar, Universitas Negeri Jakarta}

\author{
Jalan Setiabudi Jakarta Selatan
}

\begin{abstract}
Abstrak: Penelitian dan pengembangan ini bertujuan untuk menghasilkan produk berupa buku pop-up untuk pembelajaran bercerita siswa kelas III sekolah dasar dengan judul "Bu, Perutku Sakit!". Metode yang digunakan pada penelitian ini adalah metode penelitian dan pengembangan atau Research and Development (R \& D) dengan mengacu pada model pengembangan ADDIE (Analysis, Design, Develop, Implement, Evaluate). Penelitian ini melibatkan 38 siswa kelas tiga SDN Jati 03 Pagi, Pulogadung, Jakarta Timur. Penelitian ini menggunakan lembar penilaian berupa angket, wawancara, dan observasi yang dilakukan terhadap responden dengan tahapan evaluasi formatif berupa evaluasi satu-satu oleh ahli, evaluasi satu-satu oleh siswa, evaluasi kelompok kecil, dan uji coba lapangan. Hasil penilaian buku popup pada evaluasi satu-satu oleh ahli memperoleh rata-rata keseluruhan sebesar $93,26 \%$. Pada tahapan uji coba lapangan memperoleh rata-rata keseluruhan sebesar 99,46\%. Hasil penelitian menunjukkan bahwa pengembangan buku Pop-up untuk pembelajaran bercerita memperoleh kriteria sangat baik.
\end{abstract}

Kata-kata Kunci: buku bergambar, buku pop-up, Bahasa Indonesia, pembelajaran bercerita.

\section{POP-UP BOOK FOR STORYTELLING LESSON IN ELEMENTARY SCHOOL}

Abstract: The purpose of this research and development is to produce a pop-up book for storytelling in Grade III, Elementary School. The pop-up book, entitled "Bu, Perutku Sakit!".is as the result of research and development method based on ADDIE development model. This research involved 38 students of Grade III, Jati 3 Primary School, Pulogadung, East Jakarta. For formative evaluation this research used assesment forms such as questionnaire, interview guides, and observation sheets. The formative evaluation covered one-to-one evaluation by expert, oneto-one evaluation by learners, small group evaluation by learners and field test. The result of one-to-one evaluation by expert indicated the overall average of $93,26 \%$. The result of field test indicated the overall average of $99,46 \%$. The result concluded that the development of Pop-up Book for Storytelling shows a very good result.

Keywords : Picture book, pop-up book, Bahasa Indonesia, storytelling.

\section{PENDAHULUAN}

Pendidikan merupakan bagian penting dalam proses pembangunan nasional. Pendidikan membantu siswa untuk mengembangkan potensi, kecerdasan serta keterampilan yang dimilikinya. Seiring berkembangnya ilmu pengetahuan dan teknologi saat ini, dalam dunia pendidikan diperlukannya beberapa pengembangan. Pengembangan dalam dunia pendidikan dapat berupa program atau produk pembelajaran.

Pengembangan produk pembelajaran berupa bahan ajar atau media pembelajaran diharapkan dapat membantu guru dan siswa dalam proses belajar dan pembelajaran yang dilakukan di kelas. Pengembangan media pembelajaran diperlukan agar siswa mudah memahami materi pelajaran dan tertarik untuk mengikuti kegiatan belajar di kelas.

Salah satu mata pelajaran yang memerlukan pengembangan media pembelajaran yaitu Bahasa Indonesia. Bahasa Indonesia merupakan salah satu mata pelajaran yang ada di sekolah dasar yang dijadikan sebagai penghela ilmu pengetahuan. Pembelajaran Bahasa Indonesia di dalam kurikulum sekolah dasar mencakup empat keterampilan berbahasa, yaitu keterampilan menyimak, keterampilan berbicara, keterampilan membaca, dan keterampilan menulis. Pengembangan media pembelajaran pada mata pelajaran Bahasa Indonesia sangat diperlukan agar siswa mudah memahami materi pelajaran dan menguasai keempat keterampilan berbahasa. Salah satu pengembangan 
media yang diperlukan pada mata pelajaran Bahasa Indonesia ialah pengembangan media untuk pembelajaran bercerita.

Bercerita dapat diartikan sebagai suatu tuturan yang memaparkan atau menjelaskan bagaimana terjadinya suatu hal, peristiwa, dan kejadian, baik yang dialami sendiri maupun orang lain. Pada umumnya baik anak-anak maupun orang dewasa senang untuk bercerita. Bercerita merupakan salah satu bentuk kegiatan berbicara yang di pelajari oleh siswa dalam pembelajaran Bahasa Indonesia di kelas. Bentuk kegiatan bercerita bermacam-macam, seperti menceritakan pengalaman, menceritakan kembali sebuah cerita, ataupun menceritakan tentang kegiatan sehari-hari. Bercerita melatih kepercayaan diri untuk berbicara di depan orang banyak, memperkaya kosakata, mengenalkan bentuk-bentuk ekspresi dan emosi, menstimulasi daya ingat dan kreativitas, meningkatkan daya imajinasi, serta melatih kemampuan berpikir dan menghafal.

Pembelajaran bercerita dijadikan sebuah langkah awal melatih keterampilan berbicara siswa yang dilakukan di sekolah dasar. Umumnya dalam pembelajaran bercerita siswa menceritakan tentang dirinya sendiri terlebih dahulu, selanjutnya menceritakan cerita atau pengalaman yang pernah dialami siswa. Ada pula pembelajaran bercerita dengan menceritakan kembali sebuah cerita berdasarkan buku cerita, buku bergambar tertentu dan peristiwa atau pengalaman yang dialami orang lain.

Penggunaan media bercerita dapat menjadi rangsangan untuk siswa agar mudah memahami cerita dan agar mampu menceritakan kembali sebuah cerita dengan baik. Guru sebaiknya mampu mengembangkan media yang menarik dan inovatif agar dapat memberikan stimulus untuk bercerita pada siswa. Penggunaan media yang tepat, bervariasi dan menarik akan memberikan dampak yang positif bagi siswa dalam pembelajaran bercerita.

Berdasarkan wawancara dan observasi yang dilakukan saat kegiatan PKM di SDN Jati 03 Pagi Jakarta Timur, media yang digunakan guru dalam pembelajaran bercerita biasanya menggunakan gambar dari cerita di buku LKS ataupun foto tertentu. Guru belum terampil dalam mengembangkan media untuk membantu siswa dalam bercerita. Guru juga biasanya menggunakan metode ceramah untuk menjelaskan kepada siswa mengenai bercerita. Tidak jarang, guru juga mendemonstrasikan kepada siswa secara spontan bagaimana bercerita. Siswa jarang diberi kesempatan untuk berbicara lisan di depan kelas sehingga saat pembelajaran bercerita berlangsung, masih banyak siswa yang malu dan takut untuk bercerita. Kurangnya stimulus atau rangsangan berupa media bercerita yang menarik juga menyebabkan beberapa kesulitan bercerita yang dialami siswa.

Buku pop-up merupakan salah satu media yang dapat digunakan guru dalam pembelajaran bercerita di kelas. Buku pop-up merupakan sebuah buku yang memiliki bagian yang dapat bergerak atau memiliki unsur 3 dimensi. Ada tiga poin unggulan dari buku pop-up, yang pertama, buku pop-up ini praktis digunakan oleh guru serta mudah dibawa; kedua, buku pop-up berbeda dengan buku pada umumnya karena memiliki dimensi ketika buku itu dibuka sehingga menambah antusiasme siswa; ketiga, mengajak interaktivitas siswa dalam penggunaannya, siswa dapat menggunakan secara mandiri maupun berkelompok dan kegiatan belajar pun akan lebih menyenangkan. Buku popup mempunyai kemampuan untuk memperkuat kesan yang ingin disampaikan dalam sebuah cerita sehingga dapat lebih dapat terasa. Tampilan visual yang lebih berdimensi membuat cerita semakin terasa nyata ditambah lagi dengan kejutan yang diberikan dalam setiap halamannya. Gambar dapat secara tibatiba muncul dari balik halaman dengan cara ini, kesan yang ingin ditampilkan dapat lebih tersampaikan. Berdasarkan uraian latar belakang, maka fokus masalah yang akan diteliti untuk dicarikan solusinya melalui penelitian dan pengembangan ini adalah "Bagaimana mengembangkan buku pop-up yang dapat digunakan dalam pembelajaran bercerita siswa di kelas III SD?". Penelitian ini bertujuan untuk menghasilkan produk hasil pengembangan berupa buku pop-up bercerita untuk pembelajaran bercerita siswa kelas III SD. Oleh karena itu, diharapkan dapat memberi manfaat bagi siswa, guru, sekolah, dan pihak lainnya, baik secara teoretis maupun secara praktis.

Buku pop-up merupakan satu hal yang asing bagi guru dan siswa sekolah dasar. Hal tersebut terlihat dari masih banyak guru yang belum mengetahui apa itu buku pop-up. Buku pop-up biasanya berisi gambar-gambar dan tulisan-tulisan tertentu yang berisi informasi, pengetahuan, ataupun cerita yang akan disampaikan. Menurut Bunanta (1998), buku pop-up merupakan salah satu jenis buku bacaan bergambar (picture-book) yang memberikan efek tiga dimensi yang bila buku dibuka maka gambar ilustrasinya akan mencuat ke luar. Kiefer dan Tyson (2010) menjelaskan bahwa buku bergambar 
(picture-book) adalah buku yang memadukan gambar dan ide cerita dalam satu paduan yang unik. Bluemel dan Taylor (2012) menjelaskan bahwa "Pop-up book is a book that offers potential for motion and interactions through the use of paper mechanisms such as folds, scrolls, slides, tabs, or wheels". Artinya, buku pop-up adalah buku yang memberikan potensi gerak dan interaksi dengan penggunaan mekanisme kertas berupa lipatan, gulungan, geseran, sentuhan atau putaran. Adapun teknik-teknik pop-up yang umum digunakan untuk pembuatan buku pop-up ataupun kartu pop-up yaitu teknik floating layers, teknik $v$-fold, teknik multiple layers, teknik magic box, dan teknik hinged.

Karakteristik dan kriteria buku pop-up dalam aspek isi cerita dan gambar, di antaranya: (1) memiliki isi cerita, topik dan ilustrasi gambar pop-up yang menarik, relevan dengan budaya, latar belakang budaya dan disukai pembaca khususnya anak-anak; (2) cerita, tokoh, alur, dan pesan yang terkandung disesuaikan dengan perkembangan intelektual dan bahasa anak; (3) Memberikan cerita ataupun gambar yang berhubungan dengan pengalaman dan ketertarikan anak serta penulisan cerita yang mudah dipahami bagi anak; (4) Ilustrasi gambar memberikan informasi yang baru bagi anak dan membantu pembaca dalam memahami isi cerita; (5) Keterapaduan antara gambar, isi cerita dan teks yang akan disampaikan.

Adapun beberapa kriteria buku pop-up dalam aspek sajian buku dan teknik pop-up yaitu (1) buku pop-up dapat dibuka dan ditutup tanpa merusak atau merobek lembaran kertas yang lain, (2) kertas lembaran buku pop-up tidak berpotongan sehingga tidak ada halangan saat membuka atau menutup buku, (3) buku pop-up rapi saat tertutup, (4) buku popup memiliki unsur bentuk, warna, dan tekstur yang menarik, dan (5) buku pop-up tidak mudah rusak.

Menurut Yudhawati dan Haryanto (2011) pembelajaran merupakan suatu proses yang dilakukan individu untuk memperoleh perubahan perilaku yang baru secara keseluruhan, sebagai hasil pengalaman individu itu sendiri dalam interaksi dengan lingkungannya. Sama halnya dengan belajar, pembelajaran dilakukan untuk memperoleh perubahan perilaku bagi individu, namun pembelajaran berasal dari hasil pengalaman individu itu sendiri dalam interaksi dengan lingkungan. Jika belajar dilakukan oleh siswa saja, maka pembelajaran dilakukan baik oleh siswa maupun guru. Menurut Nurgiyantoro bercerita adalah salah satu kegiatan berbicara berupa tugas menceritakan kembali teks atau cerita yang dapat dilakukan dengan rangsangan gambar objek, gambar cerita ataupun buku cerita. Rangsangan ini akan memudahkan siswa untuk memahami cerita dan menceritakan kembali cerita tersebut.

Pembelajaran bercerita dapat diartikan sebagai suatu proses kegiatan terprogram untuk membuat siswa belajar secara aktif dalam menuturkan kembali sebuah cerita secara lisan, baik cerita yang benar-benar terjadi (pengalaman atau perbuatan) ataupun cerita rekaan belaka dengan alat peraga ataupun rangsangan berupa gambar, gambar susun atau buku cerita bergambar yang bertujuan untuk menyampaikan informasi, ilmu ataupun nasihat. Bercerita memiliki banyak manfaat diantaranya, mengenalkan bentuk emosi dan ekspresi, memperkaya kosakata, melatih kepercayaan diri, menstimulasi daya ingat dan kreativitas, meningkatkan daya imajinasi, dan melatih kemampuan berpikir dan menghafal.

Siswa kelas IIISD berada pada tahap operasional konkret dimana siswa belajar berdasarkan hal-hal yang konkret yang pernah dilihat atau dialaminya. Daya pikirnya juga mengalami perkembangan ke arah rasional, objektif, dan logis. Perkembangan bahasa anak meliputi penambahan kosakata, kemampuan analisis kata atau kalimat, kemampuan membentuk kalimat, dan kemampuan menggunakan kalimat yang lebih singkat dan padat yang semakin meningkat seiring perkembangan kognitif anak.

\section{METODE PENELITIAN}

Metode penelitian yang digunakan pada penelitian adalah metode penelitian pengembangan (Research and Development) dengan model pengembangan ADDIE (Analysis, Desain, Develop, Implement, Evaluate). Penelitian ini dilakukan di kelas III sekolah dasar yaitu di SDN Jati 03 Pagi Jakarta Timur pada semester satu dan dua tahun ajaran 2015/2016, pada bulan September 2015 sampai Juni 2016.

Teknik analisis data yang digunakan adalah statistik deskriptif kuantitatif, yaitu statistik yang digunakan untuk menganalisis data dengan cara menggambarkan data yang telah terkumpul sebagaimana adanya tanpa ada maksud membuat kesimpulan yang bersifat umum atau generalisasi. Teknik evaluasi data yang digunakan dalam pengembangan ini yakni evaluasi formatif. Tahap evaluasi formatif meliputi empat tahap yakni evaluasi satu-satu oleh para ahli (one to one evaluation by experts), evaluasi satu-satu oleh peserta didik (one to one 
evaluation by learners), evaluasi kelompok kecil (small group evaluation), dan uji coba lapangan (field tryout atau field testing).

\section{HASIL DAN PEMBAHASAN}

Nama produk dari hasil pengembangan ini adalah Buku Pop-up Bercerita dengan judul "Bu, Perutku Sakit!". Buku ini berisi cerita anak yang dibuat dalam bentuk pop-up pada setiap halaman ilustrasi gambarnya. Buku pop-up ini dapat digunakan pada pembelajaran Bahasa Indonesia khususnya pembelajaran bercerita untuk siswa kelas III SD. Produk berupa buku pop-up berisi cerita anak yang ilustrasi gambarnya dibuat pop-up (mencuat keluar) untuk pembelajaran Bahasa Indonesia khususnya pembelajaran bercerita untuk siswa kelas III SD. Buku pop-up ini diharapkan menjadi media yang inovatif dan menarik bagi siswa dalam pembelajaran bercerita. Buku pop-up yang dikembangkan berukuran A5 yaitu $5.8 \times 8.3$ inci dan berjumlah 24 halaman yang berisi cerita anak. Ilustrasi gambar pada buku pop-up dibuat ilustrasi gambar kartun. Pewarnaan pada buku pop-up disesuaikan dengan teori psikologi warna untuk anak yaitu warna yang cerah seperti merah, kuning, hijau, biru, dan orange. Jenis tulisan yang digunakan yaitu Print Bold dengan ukuran huruf berkisar 12-40pt. Teknik pop-up yang digunakan pada buku pop-up ini yaitu teknik $v$-fold. Material kertas yang digunakan yaitu art carton 230 gram untuk isi buku dan potongan ilustrasi pop-up. Teknik penjilidan yang digunakan yaitu teknik perfect-binding dengan material hard cover pada bagian depan dan belakang.

Tabel 1 berikut adalah penilaian ahli sastra anak berdasarkan instrumen yang digunakan pada tahapan expert review.

Tabel 1. Hasil Rekapitulasi Ahli Sastra Anak

\begin{tabular}{ccccc}
\hline $\begin{array}{c}\text { Aspek yang } \\
\text { dinilai }\end{array}$ & $\begin{array}{c}\text { Jumlah } \\
\text { Butir }\end{array}$ & $\begin{array}{c}\text { Skor } \\
\text { Kriterium }\end{array}$ & $\begin{array}{c}\text { Skor yang } \\
\text { Didapat }\end{array}$ & $\%$ \\
\hline Isi cerita & 10 & 40 & 34 & 85 \\
\hline
\end{tabular}

Berdasarkan tabel 1 di atas, dapat terlihat bahwa produk produk pop-up yang telah dikembangkan dari aspek isi cerita mendapatkan persentase penilaian oleh ahli sastra anak sebesar $85 \%$ maka dapat dikategorikan sangat baik.

Selanjutnya, Tabel 2 berikut adalah penilaian ahli bahasa berdasarkan instrumen yang digunakan pada tahapan expert review.
Tabel 2. Hasil Rekapitulasi Ahli Bahasa

\begin{tabular}{lcccc}
\hline $\begin{array}{c}\text { Aspek yang } \\
\text { dinilai }\end{array}$ & $\begin{array}{c}\text { Jumlah } \\
\text { Butir }\end{array}$ & $\begin{array}{c}\text { Skor } \\
\text { Kriterium }\end{array}$ & $\begin{array}{c}\text { Skor yang } \\
\text { Didapat }\end{array}$ & $\%$ \\
\hline 1. Kebahasaan & 8 & 32 & 30 & \\
2. Tipografi & 4 & 16 & 16 & \multirow{2}{*}{95,83} \\
\cline { 1 - 4 } \multicolumn{1}{c}{ Jumlah } & 12 & 48 & 46 & \\
\hline
\end{tabular}

Berdasarkan tabel 2 di atas, dapat dilihat bahwa produk buku pop-up yang telah dikembangkan dari aspek kebahasaan dan tipografi mendapatkan persentase penilaian oleh ahli bahasa sebesar $95,83 \%$ maka dapat dikategorikan sangat baik. Sedangkan untuk hasil penilaian ahli media pembelajaran tersaji pada Tabel 3.

Tabel 3. Hasil Rekapitulasi Ahli Media

\begin{tabular}{lcccc}
\hline Aspek yang dinilai & $\begin{array}{c}\text { Jumlah } \\
\text { Butir }\end{array}$ & $\begin{array}{c}\text { Skor } \\
\text { Kriterium }\end{array}$ & $\begin{array}{c}\text { Skor yang } \\
\text { Didapat }\end{array}$ & \% \\
\hline 1. Ilustrasi Gambar & 4 & 16 & 16 & \\
2. Sajian Buku Pop-up & 10 & 40 & 40 & \\
3. Tipografi & 4 & 16 & 16 & \multirow{2}{*}{98,95} \\
4. Kegrafikaan & 6 & 32 & 31 & \\
\cline { 1 - 4 } Jumlah & 24 & 96 & 95 & \\
\hline
\end{tabular}

Berdasarkan hasil pada tabel 3 tersebut maka dapat diartikan bahwa buku pop-up pada aspek ilustrasi gambar, sajian buku pop-up, tipografi, dan kegrafikaan mendapatkan persentase penilaian oleh ahli media sebesar 98,95\% maka dapat dikategorikan sangat baik.

Setelah dilakukan validasi produk oleh para ahli, peneliti memperbaiki produk sesuai saran dari para ahli. Tahapan selajutnya yang dilakukan adalah evaluasi formatif. Evaluasi formatif yang pertama adalah evaluasi satu-satu oleh siswa (one to one evaluation by learners). Tiga orang siswa dijadikan responden untuk tahapan evaluasi ini, setiap siswa mengisi kuesioner yang telah disediakan. Adapun hasil one-to-one evaluation, diperoleh hasil rekapitulasi angket tersaji pada Tabel 4.

Tabel 4. Hasil Rekapitulasi One-To-One Evaluation

\begin{tabular}{clcc}
\hline No. & Responden & Jumlah skor yang didapat & $\%$ \\
\hline 1 & AAF & 7 & 100 \\
2 & LR & 7 & 100 \\
3 & N & 6 & 85,71 \\
\hline & Jumlah & 26 & 95,23 \\
\hline
\end{tabular}

Berdasarkan tabel 4 di atas, dapat dilihat bahwa buku pop-up mendapatkan persentase penilaian pada tahap one-to-one evaluation sebesar 95,23\% maka dikategorikan sangat baik. 
Evaluasi formatif selanjutnya yaitu evaluasi kelompok kecil (small group evaluation). Tahapan evaluasi ini melibatkan 10 orang siswa. Berdasarkan evaluasi formatif kelompok kecil (small group) maka diperoleh hasil rekapitulasi seperti pada Tabel 5.

Tabel 5. Hasil Rekapitulasi Small Gorup Evaluation

\begin{tabular}{clcc}
\hline No. & Responden & Jumlah skor yang didapat & $\%$ \\
\hline 1 & GFS & 13 & 100 \\
2 & AS & 13 & 100 \\
3 & MRF & 12 & 92,3 \\
4 & T & 12 & 92,3 \\
5 & AZ & 13 & 100 \\
6 & BGAM & 13 & 100 \\
7 & SIP & 13 & 100 \\
8 & R & 13 & 100 \\
9 & AN & 12 & 92,3 \\
10 & HA & 12 & 92,3 \\
\hline \multicolumn{2}{r}{ Jumlah } & 126 & 96,92 \\
\hline
\end{tabular}

Berdasarkan tabel 5 di atas, dapat dilihat bahwa buku pop-up mendapatkan persentase penilaian pada tahap small group evaluation sebesar 96,92\% maka dikategorikan sangat baik.

Evaluasi formatif selanjutnya yaitu uji coba lapangan (field test). Tahapan evaluasi ini melibatkan 25 orang siswa. Berdasarkan uji coba lapangan (field test) maka diperoleh hasil rekapitulasi seperti pada Tabel 6.

Tabel 6. Hasil Rekapitulasi Field Test

\begin{tabular}{clcc}
\hline No. & Responden & Jumlah skor yang didapat & $\%$ \\
\hline 1 & MFM & 15 & $100 \%$ \\
2 & MAWS & 15 & $100 \%$ \\
3 & NYK & 15 & $100 \%$ \\
4 & ZAP & 15 & $100 \%$ \\
5 & NR & 15 & $100 \%$ \\
6 & KDR & 15 & $100 \%$ \\
7 & DPR & 14 & $93,3 \%$ \\
8 & ASR & 15 & $100 \%$ \\
9 & G & 15 & $100 \%$ \\
10 & J & 15 & $100 \%$ \\
11 & FRS & 15 & $100 \%$ \\
12 & ADS & 15 & $100 \%$ \\
13 & JA & 15 & $100 \%$ \\
14 & AZR & 15 & $100 \%$ \\
15 & ZNA & 15 & $100 \%$ \\
16 & RYD & 15 & $100 \%$ \\
17 & KHS & 15 & $100 \%$ \\
18 & RF & 15 & $100 \%$ \\
19 & KAA & 15 & $100 \%$ \\
20 & SS & 15 & $100 \%$ \\
\hline
\end{tabular}

Tabel 6 (Lanjutan). Hasil Rekapitulasi Field Test

\begin{tabular}{clcc}
\hline No. & Responden & Jumlah skor yang didapat & $\%$ \\
\hline 21 & F & 14 & $93,3 \%$ \\
22 & SID & 15 & $100 \%$ \\
23 & AWK & 15 & $100 \%$ \\
24 & AF & 15 & $100 \%$ \\
25 & MF & 15 & $100 \%$ \\
\hline & Jumlah & 373 & $99,46 \%$ \\
\hline
\end{tabular}

Berdasarkan tabel di atas, terlihat bahwa buku pop-up mendapatkan persentase penilaian pada tahap field test sebesar 99,46\% maka dikategorikan sangat baik.

\section{PENUTUP}

\section{Kesimpulan}

Penelitian dan pengembangan ini menghasilkan buku pop-up untuk pembelajaran bercerita siswa kelas III SD dengan judul “Bu, Perutku Sakit!". Buku pop-up "Bu, Perutku Sakit!" yang dikembangkan mengacu pada model pengembangan ADDIE (Analysis, Design, Development, Implementation, Evaluation).

Berdasarkan hasil expert review yang dilakukan oleh tiga orang ahli (ahli sastra anak, ahli media, dan ahli bahasa) rata-rata hasil penilaian buku popup mendapatkan persentase sebesar 93,26\% dengan kriteria sangat baik. Hasil rata-rata penilaian buku pop-up oleh siswa pada tahap one to one evaluation mendapatkan persentase sebesar 95,23\% dengan kriteria sangat baik. Hasil rata-rata penilaian buku pop-up oleh siswa pada tahapan small group evaluation mendapatkan persentase sebesar $96,92 \%$ dengan kriteria sangat baik.

Hasil observasi pada tahapan small group evaluation menunjukkan penggunaan waktu yang dibutuhkan guru dan siswa saat pembelajaran bercerita dengan menggunakan buku pop-up yaitu hanya 1 jam pelajaran (35 menit). Guru dan siswa terlihat tidak mengalami kesulitan saat menggunakan buku pop-up meskipun guru baru pertama kali menggunakan buku pop-up di kelas serta tidak perlu adanya bahan ajar atau media tambahan untuk mendukung buku pop-up. Hasil wawancara dengan guru dan siswa pada tahap small group evaluation menunjukkan, guru dan siswa sangat tertarik pada buku pop-up dan ingin menggunakan buku pop-up sebagai media untuk pembelajaran Bahasa Indonesia selanjutnya khususnya pembelajaran bercerita.

Hasil rata-rata penilaian buku pop-up oleh siswa pada tahap field test mendapatkan persentase sebesar 99,46\% dengan kriteria sangat baik. Hasil observasi 
pada tahap field test menunjukkan penggunaan waktu yang dibutuhkan guru dan siswa saat pembelajaran bercerita dengan menggunakan buku pop-up yaitu hanya 50 menit. Guru dan siswa terlihat tidak mengalami kesulitan saat menggunakan buku popup. Siswa sangat tertarik dan minat untuk melakukan kegiatan bercerita dengan menggunakan buku pop-up sebagai media bercerita. Hasil wawancara dengan guru menunjukkan pada tahap field test, guru berpendapat buku pop-up sangat bagus dan guru ingin menggunakan buku pop-up sebagai media untuk pembelajaran bercerita selanjutnya.

Berdasarkan hasil evaluasi formatif expert review, one to one evaluation, small group evaluation, dan field test dapat dinyatakan buku pop-up bercerita dengan judul “Bu, Perutku Sakit!” merupakan produk yang valid dan dapat digunakan sebagai media bercerita pada pembelajaran bercerita di kelas III sekolah dasar.

\section{Saran}

Berdasarkan kesimpulan dan implikasi yang telah dikemukakan maka peneliti menyampaikan beberapa saran sebagai berikut. Pertama, pada pembelajaran bercerita di kelas, sebaiknya guru menggunakan media yang lebih inovatif dan menarik bagi siswa agar terciptanya suasana belajar yang menyenangkan dan tidak membosankan. Kedua, dalam penggunaan buku pop-up untuk pembelajaran bercerita, sebaiknya guru lebih kreatif untuk menyampaikan cerita dengan mimik, suara, ataupun gaya cerita akan menjadi contoh yang baik untuk siswa, sehingga siswa akan menirukan dan kemampuan bercerita siswa diharapkan dapat berkembang. Ketiga, siswa dapat menggunakan buku pop-up secara individu maupun kelompok. Keempat, siswa dapat membawa buku pop-up saat bercerita ke depan kelas. Kelima, sekolah diharapkan dapat menjadikan buku pop-up sebagai salah satu alternatif media bercerita yang inovatif dan menarik bagi siswa. Keenam, peneliti selanjutnya dapat mengembangkan produk yang lebih baik lagi dengan menggunakan lebih dari satu teknik pop-up sehingga bisa lebih menarik.

\section{DAFTAR PUSTAKA}

Bluemel, N. \& Taylor, R. (2012). Pop-up books: A guide for teachers and librarians. Santa Barbara: Libraries Unlimited.

Bunanta, M. (1998). Problematika penulisan cerita rakyat untuk anak di Indonesia. Jakarta: Balai Pustaka.

Kiefer, B.Z. \& Tyson, C.A. (2010). Charlotte Huck's children's literature. New York: Mc. Graw Hill Higher Education.

Yudhawati \& Haryanto. (2011). Teori-teori dasar psikologi pendidikan. Jakarta: Prestasi Pustaka 